\title{
Analisis Dan Perancangan Alat Pendeteksi Tekanan Kerja Pompa Bahan Bakar Efi (Electronic Fuel Injection) Dengan Menggunakan Sensor Tekanan
}

\author{
Analysis And Development Of Pressure Fuel Pump Detector In Efi \\ (Electronic Fuel Injection) System
}

\author{
Toto Sugiarto, Andrizal \& Yandri Anto
}

Jurusan Teknik Otomotif UNP. Email : totosugiarto@gmail.com, andrizal_55@yahoo.co.id)

\begin{abstract}
An EFI cars (Electronic Fuel Injection) is not equipped with a pressure fuel pump indicator, so the driver does not know the the fuel pump performance. If the fuel pump work under the standard, the engine is not responsive to acceleration, engine temperature can be increased and the performance of the engine is lowered. This research are trying to design a fuel pump pressure detector using a pressure sensor. The research methodology used is the Research and Development $(R \& D)$ consisting of product design, design validation, design revisions, and test products. This study used three product design because the design of the first and the second has not been as expected. The third design uses a comparator circuit as the controller three indicator LED (Light Emitting Diode). If the fuel pump working pressure of $2,1 \mathrm{~kg} / \mathrm{cm}^{2}-2.5 \mathrm{~kg} / \mathrm{cm}^{2}$, the three colored LED green, yellow and red lights up. If the fuel pump working pressure of $1.6 \mathrm{~kg} / \mathrm{cm}^{2}-2,0 \mathrm{~kg} / \mathrm{cm}^{2}$, the two LED will light up the colors yellow and red. If the fuel pump working pressure of $1,0 \mathrm{~kg} / \mathrm{cm}^{2}-1.5 \mathrm{~kg} / \mathrm{cm}^{2}$, it is only one red LED are illuminated. A comparison between the changes in pressure to produce the output voltage linear data and repeatibility $=0$.
\end{abstract}

Keywords: EFI System, Electronic Fuel Injection, fuel pumps pressure, pressure sensors

\section{PENDAHULUAN}

Perkembangan ilmu pengetahuan dan teknologi membawa dampak pada semua sektor. Salah satu sektor yang berkembang pesat saat ini yaitu teknologi otomotif. Sehingga menghasilkan kendaraan dengan kualitas dan performa yang lebih baik, mudah pengoperasiannya, hemat bahan bakar dan ramah lingkungan. Penerapan sistem ini dapat kita lihat pada sistem bahan bakar menggunakan EFI (Electronic Fuel Injection), sistem pengapian menggunakan DLI (Distributor Less Ignition), Power Window, sistem rem menggunakan $A B S$ (Anti-Lock Brake System).

Keunggulan lain dari sistem EFI yaitu perbandingan bahan bakar dengan udara dapat diperoleh pada setiap tingkat putaran mesin, mempunyai respon sesuai dengan perubahan posisi katup gas (throttle) menggunakan koreksi campuran bahan bakar dengan udara yang baik, efesiensi pemasukan bahan bakar dan udara yang sempurna. Sehingga dapat meningkatkan efesiensi penggunaan bahan bakar, kinerja mesin lebih maksimal, pengoperasian mesin lebih mudah, memperpanjang umur dan daya tahan mesin, serta emisi gas buang lebih rendah.

Sistem bahan bakar EFI memiliki pompa bahan bakar yang terletak di dalam tangki bahan bakar. Pompa bahan bakar adalah salah satu bagian terpenting bagi mesin, yang merupakan suatu alat untuk mengalirkan bahan bakar ke pipa pembagi dan menyemprotkan bahan bakar ke dalam intake manifold melalui injektor hingga terjadi proses pembakaran di dalam silinder. Agar penyemprotan bahan bakar memiliki volume dan durasi yang tepat maka injektor 
dikontrol oleh ECU (Electronic Control Unit) berdasarkan input sinyal dari berbagai sensor seperti MAP (Manifod Absolute Pressure), TPS (Throotle Position Sensor), ECT (Engine Coolant Temperature), IAT (Intake Air Temperature), KNK (Knock Sensor), VSS (Vehicle Speed Sensor), Oxygen Sensor dan sensor yang lainnya.

Peningkatan kendaraan dari tahun ke tahun di Indonesia sangat pesat, pengeluaran kendaraan dari pabrik mulai tahun 2000 khususnya mobil, yang beredar di masyarakat semuanya sudah memakai sistem EFI. Pada umumnya mobil yang beredar di masyarakat belum dilengkapi dengan alat pendeteksi kondisi tekanan pompa bahan bakar atau pressure sensor.

Sensor tekanan merupakan sensor yang menginderai perubahan tekanan akibat kevacuman atau pemampatan yang akan merubah tekanan menjadi tegangan. Berdasarkan latar belakang masalah di atas dan perkembangan teknologi elektronika, maka peneliti mencoba merancang suatu alat yang mampu mendeteksi tekanan kerja pompa bahan bakar pada sistem EFI menggunakan pressure sensor tipe SS204. Sensor tekanan ini mampu untuk mendeteksi penurunan tekanan kerja pada pompa bahan bakar, selanjutkan akan memberikan indikator kepada pengemudi di dalam ruang pengemudi berupa LED (Light Emiting Diode) sebagai lampu indikator tekanan kerja pompa bahan bakar. Sehingga dengan adanya alat pendeteksi ini nantinya masalah di atas mampu diminimalisir dan juga memudahkan bagi pengemudi mengetahui kondisi tekanan pompa bahan bakar.

Dalam jurnal ini penulis akan mencoba untuk mendeskripsikan perancangan dan cara membuat alat pendeteksi tekanan kerja pompa bahan bakar EFI menggunakan pressure sensor tipe SS204. Selain itu juga penulis menganalisis unjuk kerja alat pendeteksi tekanan kerja pompa bahan bakar EFI menggunakan pressure sensor tipe SS204.
Sistem aliran bahan bakar dengan tekanan kerja tertentu melalui pompa bensin mensuplai bensin dari tangki, sampai ke injektor. Injektor menyemprotkan bensin ke setiap saluran masuk silinder motor, dengan jumlah bahan bakar yang disesuaikan dengan kebutuhan unjuk kerja (performance) motor. ECU berfungsi mengatur volume penyemprotan bensin berdasarkan masukan dari sensorsensor seperti sensor putaran, beban motor, situasi kerja atau pengendalian motor, suhu air pendingin dan suhu udara masuk serta variabel lainnya.

Komponen-komponen yang digunakan untuk menyalurkan bahan bakar ke silinder terdiri atas tangki bahan bakar, pompa bahan bakar (fuel pump), saringan bahan bakar (fuel filter), pipa penyalur (delivery pipe), katup pengatur tekanan (pressure regulator), injektor dan saluran pengembali (return line).

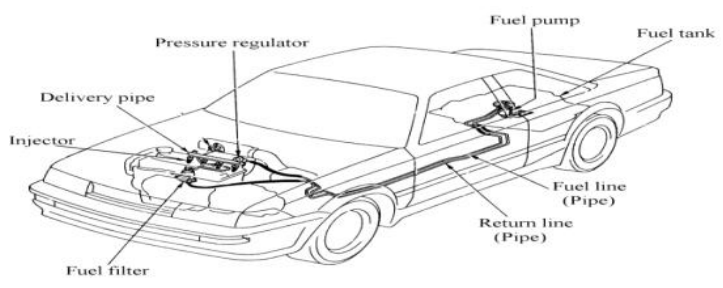

Gambar 1. Sistem Bahan Bakar (Fuel System) (Sumber. Toyota New Step 1,1996: MES 3-72)

Penjelasan komponen-komponen sistem bahan bakar adalah sebagai berikut: Tangki Bahan Bakar

Tangki bahan bakar berfungsi untuk menampung bahan bakar sebelum disalurkan ke dalam sitem bahan bakar. Tangki bahan bakar dilengkapi dengan separator atau pemisah yang berfungsi sebagai penahan damper bila kendaraan berhenti secara tiba-tiba dan bila berjalan dijalan yang tidak rata, goncangan bahan bakar didalam tangki pada saat kendaraan mendapat goncangan.

\section{Sistem Bahan Bakar EFI}




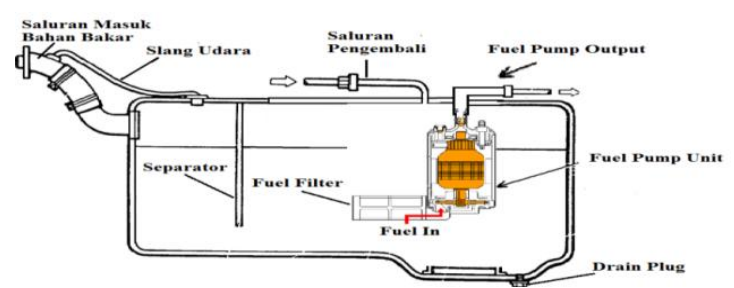

Gambar 2. Konstruksi Tangki Bahan Bakar (Sumber. Training Manual Toyota Controlled System, $2004: 67$ )

Tangki bahan bakar dilengkapi dengan pipa untuk pengisian bahan bakar. Tangki bahan bakar pada umumnya terletak dibagian belakang kendaraan yang bertujuan untuk mencegah kebocoran bahan bakar bila terjadi benturan dan terbuat dari plat baja tipis pada bagian dalam tangki dilapisi dengan pelapis anti karat.

\section{Pompa Bahan Bakar}

Secara umum pompa bahan bakar ada dua tipe yaitu, pompa bahan bakar yang terpasang di luar tangki (in-line type) dan pompa bahan bakar yang terpasang di dalam tangki (in-tank type). Kedua tipe pompa bahan bakar ini biasa disebut wet type, walaupun motor bersatu dengan pompa dan bagian dalam pompa terisi dengan bahan bakar. Pompa bahan bakar digerakkan oleh motor listrik magnet permanen yang dikonstruksikan menjadi satu unit dengan rumah pompa.

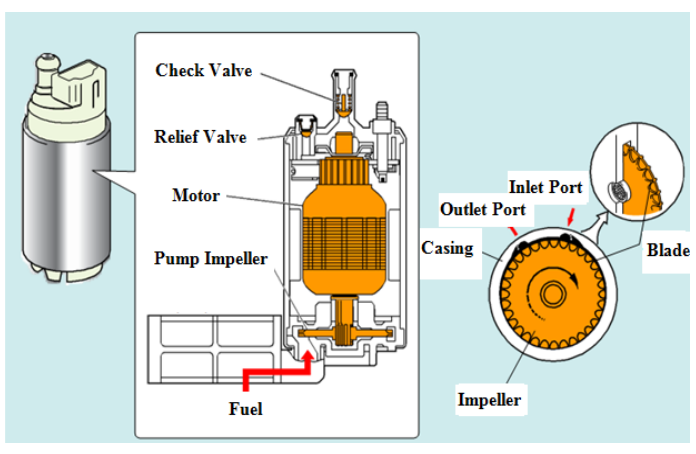

Gambar 3. Konstruksi Pompa Bahan Bakar In Tank Type (Sumber. Tehnical Training Agency EFI. hal 20)

Penempatan pompa bensin listrik berada dalam tangki bahan bakar merupakan alternatif pemasangan pompa yang terbaik, karena pompa akan terlindung dari kotoran yang menempel, juga bunyi pompa akan bisa diredam, serta pompa tidak memerlukan perawatan khusus.

Menurut Buku Training Manual Toyota Soluna (2004) " Pompa bahan bakar jenis in-tank tipe, memiliki beberapa komponen yang mempengaruhi tekanan kerja pompa bahan bakar yaitu, fuel pump filter, pump impeller, keausan sikat (brus) positif dan negatif, saluran bahan bakar, fuel filter, dan pressure regulator".

Sensor Tekanan

Sensor tekanan adalah sensor untuk mengukur tekanan suatu zat. Satuan tekanan sering digunakan untuk mengukur kekuatan dari suatu cairan atau gas. Satuan tekanan dapat dihubungkan dengan satuan volume dan suhu. Semakin tinggi tekanan di dalam suatu tempat dengan isi yang sama, maka suhu akan semakin tinggi. Rumus dari tekanan dapat juga digunakan untuk menerangkan mengapa pisau yang diasah dan permukaannya menipis menjadi tajam. Semakin kecil luas permukaan, dengan gaya yang sama akan dapatkan tekanan yang lebih tinggi. Prinsip kerja dari sensor tekanan ini adalah mengubah tegangan mekanis menjadi sinyal listrik yang didasarkan pada prinsip tahanan pengantar berubah dengan panjang dan luas penampang.

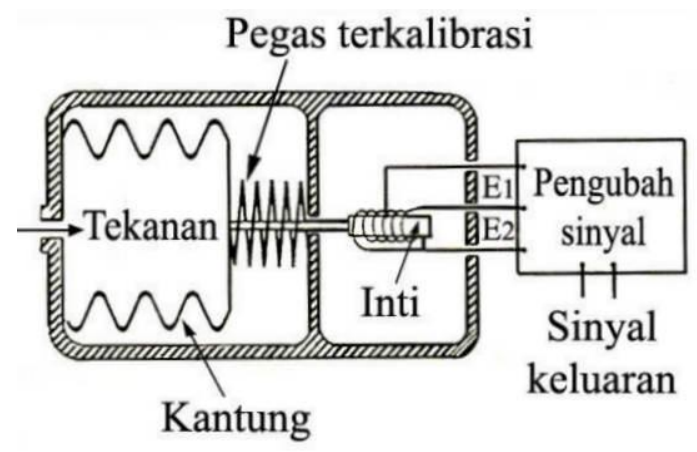

Gambar 4. Kontruksi Dasar Sensor Tekanan (Sumber. http://m-edukasi.net/jenis sensor)

Cara kerja sensor tekanan pada gambar di atas yaitu, perubahan tekanan di dalam kantung menyebabkan perubahan posisi inti kumparan sehingga mengakibatkan perubahan induksi magnetik pada kumparan. Kumparan yang digunakan 
adalah kumparan $C T$ (Center Tap), dengan demikian apabila inti mengalami pergeseran maka induktansi pada salah satu kumparan bertambah sementara induktansi pada kumparan yang lain berkurang. Kemudian pengubah sinyal berfungsi untuk mengubah induktansi magnetik yang timbul pada kumparan menjadi tegangan yang sebanding.

\section{Pressure Sensor Tipe SS204}

Jenis pressure sensor tipe SS204 adalah sensor tipe piezoelektrik secara luas sensor tersusun dari transduser. Piezolektrisitas adalah kemampuan dari suatu benda untuk menghasilkan potensial listrik sebagai respon terhadap tekanan mekanik yang diberikan. Efek piezoelektrik ada dua macam yaitu efek piezoelektrik langsung (direct piezoelectric effect) dan efek piezoelektrik balikan (converse piezoelectric effect). Efek piezoelektrik langsung adalah produk potensial listrik akibat adanya tekanan mekanik. Sedangkan efek piezoelektrik balikan adalah produksi tekanan akibat pemberian tegangan listrik.

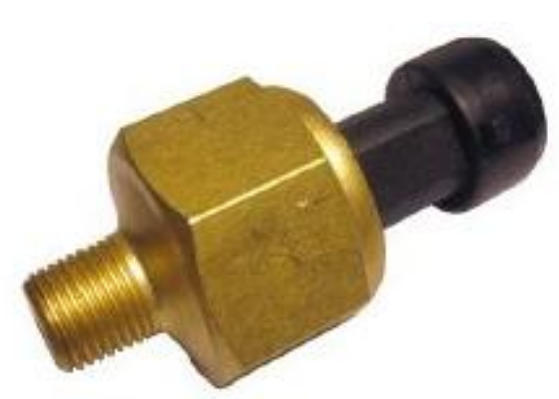

Gambar 5. Pressure Sensor Tipe SS204

(Sumber.http://www.pressuresensorsuppliers.c om/SS204-Series)

Sensor piezoelektrik dapat digunakan untuk mengukur besarnya tegangan akibat perubahan tekanan. Bahan piezoelektrik menghasilkan potensial listrik ketika mendapatkan tekanan secara mekanik. Sensor piezoelektrik muatan positif dan negatif terpisah namun tersebar secara simetris, sehingga bersifat netral. Masing-masing sisi membentuk kutub listrik. Ketika suatu tekanan mekanik diterima oleh piezoelektrik bentuk simetris dari dari tiap-tiap muatan listrik tersebut berubah menjadi tidak simetris yang akan menghasilkan tegangan listrik. Adapun karakteristik pressure sensor tipe SS204, seperti pada tabel di bawah ini.

Tabel 1. Spesifikasi Parameter Pressure Sensor Tipe SS204

\begin{tabular}{|c|l|l|}
\hline No & \multicolumn{1}{|c|}{ Parameter } & \multicolumn{1}{c|}{ Keterangan } \\
\hline 1 & Suply Voltage & 5VDC \\
\hline 2 & Output Signal & $0.5 \sim 4.5 \mathrm{VDC}$ \\
\hline 3 & Measuring Range & $(250 \mathrm{KPa})$ \\
\hline 4 & Proof Pressure & $150 \% \mathrm{FS}$ \\
\hline 5 & Accuracy & $1 \%$ \\
\hline 6 & Operating Temp & $-20 \sim 120^{\circ} \mathrm{C}$ \\
\hline 7 & Storage Temp & $-40 \sim 120^{\circ} \mathrm{C}$ \\
\hline 8 & Pressure Port & $1 / 8 \mathrm{NPT} ; \mathrm{G} 1 / 4$ \\
\hline 9 & Electrical connection & 3 Pin Packard \\
\hline 10 & Sealing Rating & IP65 \\
\hline 11 & Housing & Brass dan Stainless Steel \\
\hline 12 & Diafragma & Stainless Stell \\
\hline
\end{tabular}

http://www.pressuresensorsuppliers.com/SS204Series

Spesifikasi keterangan pin konektor pressure sensor tipe SS204, seperti pada tabel 2.

Tabel 2. Spesifikasi Konektor Pressure Sensor Tipe SS204

\begin{tabular}{|c|c|c|c|}
\hline Konektor & Pin & Fungsi & Warna \\
\hline & A & Massa & Hitam \\
\hline & B & Input $\mathrm{V}+$ & Merah \\
\hline & $\mathrm{C}$ & Output V - & Biru \\
\hline
\end{tabular}

http://www.pressuresensorsuppliers.com/SS204Series

\section{METODOLOGI}

\section{Jenis Penelitian}

Penelitian ini merupakan jenis penelitian Research and Development (Penelitian dan Pengembangan), dimana peneliti merancang untuk menghasilkan produk tertentu, dan menguji keefektifan produk tersebut.

\section{Strategi Research and Development Desain produk}

Desain alat pendeteksi tekanan kerja pompa bahan bakar menggunakan pressure sensor tipe SS204 dapat dilihat pada gambar 6. Prinsip dasar perancangan pada bagian deteksi tekanan pompa bahan bakar 
menggunakan pressure sensor tipe SS204, yaitu pada saat pompa bahan bakar mengalirkan bahan bakar dari tangki bahan ke pipa pembagi, maka saluran bahan bakar diparalelkan pada pressure sensor. Tekanan kerja di dalam pipa pembagi dipertahankan oleh katup pengontrol. Tekanan bahan bakar di dalam pipa pembagi juga dideteksi oleh pressure sensor, pada saat yang sama tegangan $5 \mathrm{~V}$ juga dialirkan ke terminal 3 pressure sensor.

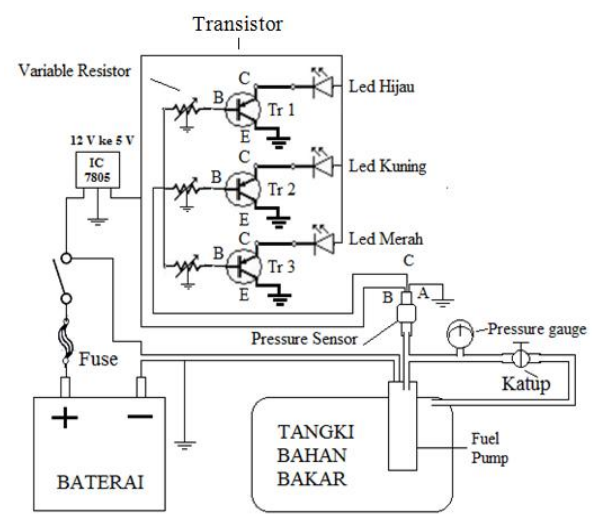

Gambar 6. Desain Alat

\section{Pembuatan Produk}

Tahapan perancangan dan pembuatan produk berdasarkan desain alat pada gambar 6, meliputi rangkaian pengontrolnya. Adapun langkah-langkah yang dilakukan adalah sebagai berikut:

a. Menyiapkan alat dan bahan

b. Merakit komponen-komponen seperti desain alat gambar 6, di project board.

c. Setelah selesai, dilakukan uji coba alat.

d. Jika hasil pengujian telah sesuai dengan yang diharapkan dilanjutkan dengan membuat di PCB.

\section{Validasi desain}

Menurut Sugiono (2013: 302), " Validasi desain merupakan proses kegiatan rancangan produk, secara rasional akan lebih efektif dari produk lama atau tidak". Validasi desain dalam perancangan dan membuat alat pendeteksi kondisi tekanan kerja pompa bahan bakar dilakukan melalui pendapat para pakar yang sudah berpengalaman untuk menilai produk yang akan dirancang tersebut.

\section{Revisi desain}

Revisi desain dilakukan dua kali, karena desain I dan desain II belum menghasilkan output seperti yang diharapkan. Revisi desain dilakukan dengan cara diskusi dengan dosen yang mumpuni dibidang elektronika.

\section{Uji coba produk}

a. Putar switch ON, maka arus mengalir dari + baterai - fuse - switch (output switch terbagi dua) yaitu tegangan $12 \mathrm{~V}$ mengalir ke fuel pump - massa (menyebabkan fuel pump berputar dan mensuplai bahan bakar. Selanjutnya tegangan $12 \mathrm{~V}$ masuk ke rangkaian pembagi tegangan (IC 7805 ) dengan tegangan konstan $5 \mathrm{~V}$ (output) terminal B pressure sensor.

b. Tekanan bahan bakar di ukur menggunakan pressure gauge tipe bourdon tube dan dipertahankan pada tekanan kerja injektor seperti Toyota Corolla Soluna Engine 5A-FE dengan kran bahan bakar pengganti pressure regulator. Pada saat fuel pump mensuplai bahan bakar dari tangki bahan bakar maka tekanan bahan bakar dideteksi oleh pressure sensor. Selanjutnya tegangan output pressure sensor pada terminal $\mathrm{C}$ akan masuk ke rangkaian penguat berupa variasi tegangan $0,5-4,5 \mathrm{~V}$, yang kemudian digabungkan dengan rangkaian pengontrol (variabel resistor) untuk memberikan tiga indikator led dengan warna hijau, kuning dan merah berdasarkan tekanan kerja pompa bahan bakar. Jika tekanan kerja pompa bahan bakar berada dalam spesifikasi $2,1 \mathrm{~kg} / \mathrm{cm}^{2}-2,6 \mathrm{~kg} / \mathrm{cm}^{2}$ pada saat kondisi idling $800 \mathrm{rpm}$ maka led menyala keseluruhan, led warna hijau dikontrol menyala pada kondisi putaran idling (spesifikasi Toyota Soluna Engine 5A-FE) dengan tekanan kerja pompa bahan bakar di dalam pipa pembagi berkisar antara $2,1 \mathrm{~kg} / \mathrm{cm}^{2}$ - 
$2,5 \mathrm{~kg} / \mathrm{cm}^{2}$, led kuning dikontrol pada tekanan antara $1,6 \mathrm{~kg} / \mathrm{cm}^{2}-2,0 \mathrm{~kg} / \mathrm{cm}^{2}$, dan led warna merah dikontrol pada tekanan antara $1,0 \mathrm{~kg} / \mathrm{cm}^{2}-1,5 \mathrm{~kg} / \mathrm{cm}^{2}$.

\section{HASIL}

\section{Desain Produk}

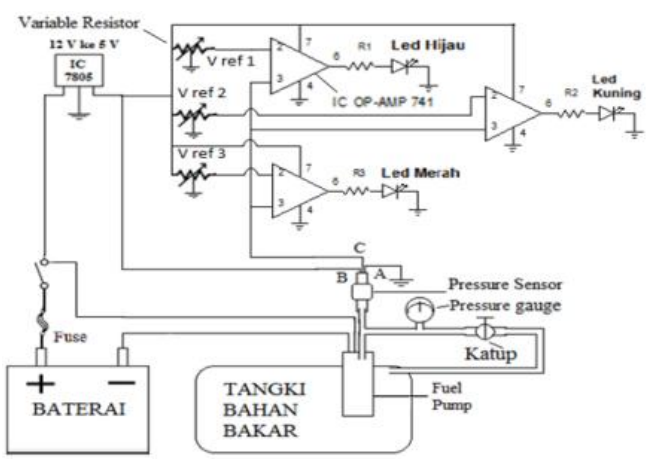

Gambar 7. Desain alat pendeteksi tekanan kerja pompa bahan bakar EFI

IC Op-Amp 741 pada gambar di atas berfungsi sebagai rangkaian komparator. Pin 2 merupakan input tegangan referensi $\left(\mathrm{V}_{\text {ref }}\right)$. Tegangan referensi terdiri dari tiga tegangan referensi $\mathrm{V}_{\text {ref } 1}=3,50 \mathrm{~V}, \mathrm{~V}_{\text {ref }} 2=2,80 \mathrm{~V}$ dan $\mathrm{V}_{\text {ref }} 2=$ $1,60 \mathrm{~V}$. Pin 3 terhubung dengan tegangan output sensor. Jika tegangan pada pin 3 melebihi atau sama dengan tegangan referensi pin 2 maka output dari IC 741 (pin 6) dalam keadaan logic high (1) dan jika tegangan pin 3 kurang dari tegangan referensi pin 2 maka output IC 741 (pin 6) dalam keadaan logic low (0).

\section{Hasil Pengujian}

Rancangan desain sesuai dengan yang diharapkan, jika tekanan kerja pompa bahan bakar berada pada tekanan 1,0 $\mathrm{kg} / \mathrm{cm}^{2}-1,5 \mathrm{~kg} / \mathrm{cm}^{2}$ maka led warna merah hidup dari menyala redup hingga menyala maksimal pada tekanan $1,5 \mathrm{~kg} / \mathrm{cm}^{2}$. Indikator ini menunjukkan tekanan kerja pompa bahan bakar dibawah spesifikasi dan pompa tidak layak dioperasikan, sehingga disarankan pergantian pompa bahan bakar.

Data hasil pengujian produk (alat pendeteksi) adalah seperti tabel di bawah ini.
Tabel 3. Format Pengambilan Data Pengujian

\begin{tabular}{|c|c|c|c|c|c|}
\hline \multirow{2}{*}{$\begin{array}{l}\text { Tekanan } \\
\left(\mathrm{kg} / \mathrm{cm}^{2}\right)\end{array}$} & \multicolumn{3}{|c|}{$\begin{array}{l}\text { Tegangan Pengujian } \\
\text { (V) }\end{array}$} & \multirow{2}{*}{$\begin{array}{l}\text { Rata-Rata } \\
\text { Tegangan } \\
\text { (V) }\end{array}$} & \multirow[t]{2}{*}{$\begin{array}{l}\text { Indikator Led } \\
\text { (warna) }\end{array}$} \\
\hline & I & II & III & & \\
\hline 2,5 & 4,503 & 4,502 & 4,504 & 4,503 & $\left.\mathrm{H}, \mathrm{K}, \mathrm{M}^{*}\right)$ \\
\hline 2,4 & 4,414 & 4,416 & 4,418 & 4,416 & $\left.\mathrm{H}, \mathrm{K}, \mathrm{M}^{*}\right)$ \\
\hline 2,3 & 4,040 & 4,050 & 4,060 & 4,050 & $\left.\mathrm{H}, \mathrm{K}, \mathrm{M}^{*}\right)$ \\
\hline 2,2 & 3,831 & 3,920 & 3,926 & 3,892 & $\left.\mathrm{H}, \mathrm{K}, \mathrm{M}^{*}\right)$ \\
\hline 2,1 & 3,713 & 3,759 & 3,753 & 3,741 & $\left.\mathrm{H}, \mathrm{K}, \mathrm{M}^{*}\right)$ \\
\hline 2,0 & 3,625 & 3,595 & 3,617 & 3,612 & $\mathrm{~K}, \mathrm{M} *)$ \\
\hline 1,9 & 3,451 & 3,483 & 3,487 & 3,473 & $\left.\mathrm{~K}, \mathrm{M}^{*}\right)$ \\
\hline 1,8 & 3,320 & 3,307 & 3,312 & 3,334 & $\mathrm{~K}, \mathrm{M}$ *) \\
\hline 1,7 & 3,168 & 3,168 & 1,168 & 3,168 & $\mathrm{~K}, \mathrm{M} *)$ \\
\hline 1,6 & 2,960 & 3,065 & 2,960 & 2,995 & $\left.\mathrm{~K}, \mathrm{M}^{*}\right)$ \\
\hline 1,5 & 2,841 & 2,882 & 2,842 & 2,885 & M*) \\
\hline 1,4 & 2,703 & 2,681 & 2,720 & 2,701 & $\left.M^{*}\right)$ \\
\hline 1,3 & 2,529 & 2,554 & 2,510 & 2,531 & $\left.M^{*}\right)$ \\
\hline 1,2 & 2,350 & 2,343 & 2,331 & 2,341 & $\left.M^{*}\right)$ \\
\hline 1,1 & 2,205 & 2,209 & 2,198 & 2,204 & $\left.\mathrm{M}^{*}\right)$ \\
\hline 1,0 & 1,981 & 2,005 & 1,985 & 1,990 & $\left.M^{*}\right)$ \\
\hline
\end{tabular}

Keterangan *)

$\mathrm{H}-\mathrm{K}-\mathrm{M}=$ Led hijau, kuning dan merah menyala serentak

K-M = Hijau Mati, Kuning dan Merah menyala

M=Hijau dan Kuning Mati, Merah menyala

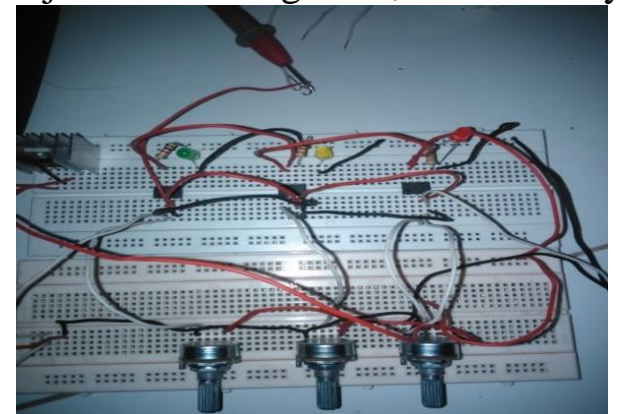

Gambar 8. Pengujian Indikator Led pada Tekanan $1,0 \mathrm{~kg} / \mathrm{cm}^{2}$

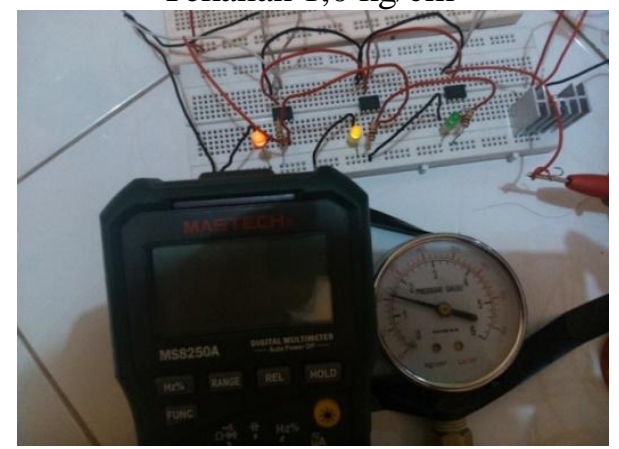

Gambar 9. Pengujian Indikator Led pada Tekanan $1,6 \mathrm{~kg} / \mathrm{cm}^{2}$

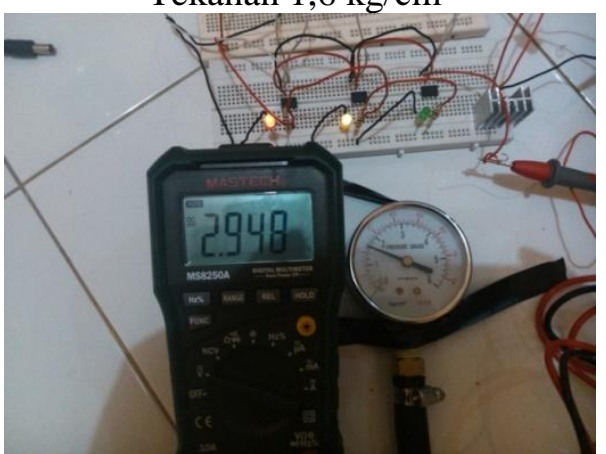

Gambar 10. Pengujian Indikator Led pada tekanan $1,65 \mathrm{~kg} / \mathrm{cm}^{2}$ 
Pengujian pada gambar 10, saat led warna merah menyala maksimal dan LED warna kuning menyala redup, hingga menyala maksimal pada tekanan kerja pompa bahan bakar pada tekanan 2,0 $\mathrm{kg} / \mathrm{cm}^{2}$ seperti gambar di bawah ini. Indikator ini menunjukkan tekanan kerja pompa bahan bakar dibawah spesifikasi dan pompa masih layak dioperasikan, yang perlu dilakukan hanya membersihkan saringan pompa bahan bakar.

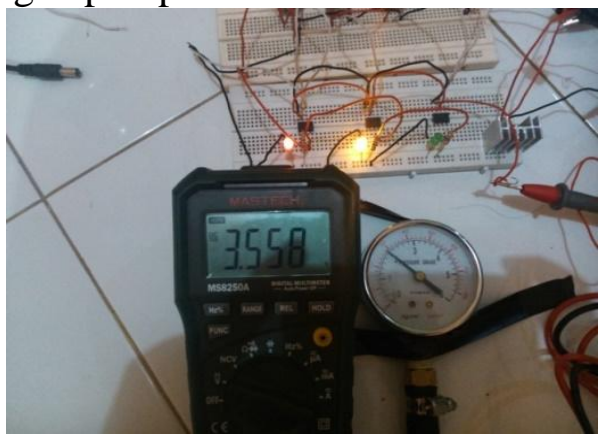

Gambar 11. Pengujian Indikator Led pada Tekanan $2,0 \mathrm{~kg} / \mathrm{cm}^{2}$

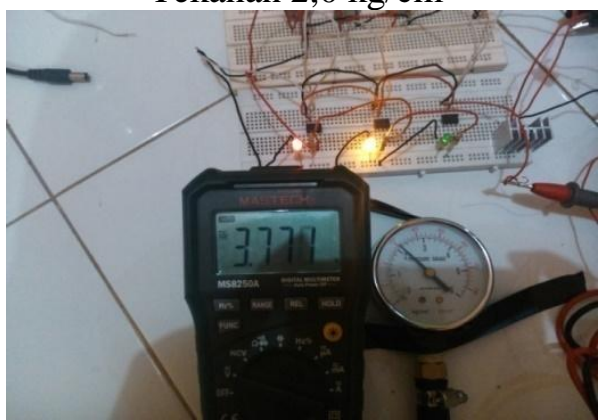

Gambar 12. Pengujian Indikator Led pada Tekanan $2,1 \mathrm{~kg} / \mathrm{cm}^{2}$

Gambar 12, saat led warna merah dan kuning menyala maksimal, dan led warna hijau mulai menyala, tetapi masih redup hingga menyala maksimal pada tekanan kerja pompa bahan bakar pada tekanan 2,5 kg/ $\mathrm{cm}^{2}$ seperti gambar 13 . Indikator ini menunjukkan tekanan kerja pompa bahan bakar pada spesifikasi dan pompa masih layak dioperasikan tanpa memberikan perlakuan.

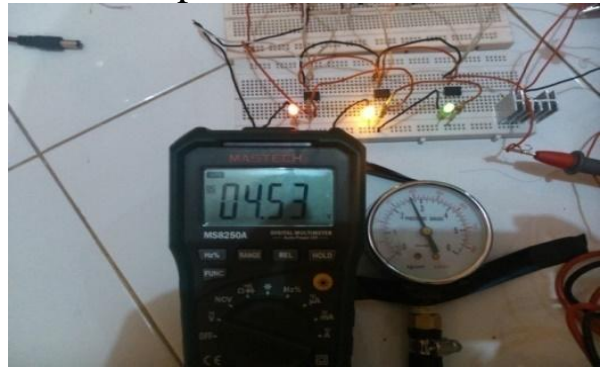

Gambar 13. Pengujian Desain

\section{PEMBAHASAN}

\section{Linearitas}

Hasil pengujian pada tabel 3, menghasilkan grafik linearitas seperti gambar di bawah ini. Tekanan kerja pompa bahan bakar sebagai stimulus pada sumbu $\mathrm{x}$ dan output berupa variasi tegangan rata-rata pada sumbu y dapat dilihat pada gambar 14 .

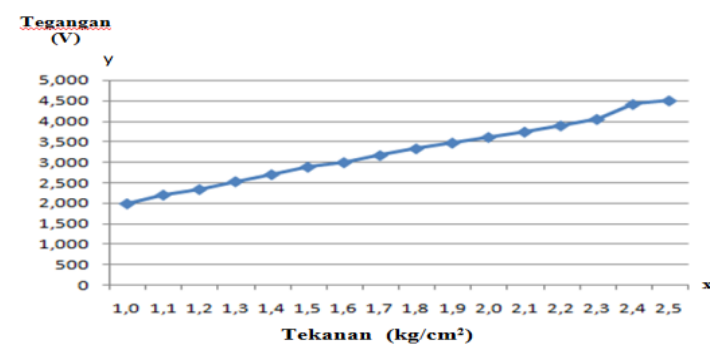

Gambar 14. Grafik Linearitas berdasarkan Output Tegangan Rata-Rata

\section{Repeatibility}

Hasil pengujian pada tabel 3 , menghasilkan grafik repeatibility seperti gambar di bawah ini. Tekanan kerja pompa bahan bakar sebagai stimulus pada sumbu $\mathrm{x}$ dan output berupa variasi tegangan dari pengujian I, II, III pada sumbu y. Berdasarkan gambar 15, meskipun dilakukan $3 \mathrm{x}$ pengujian, data yang dihasilkan cendrung sama, artinya pengulangan pengambilan data (repeatibility) tetap menghasilkan data yang sama.

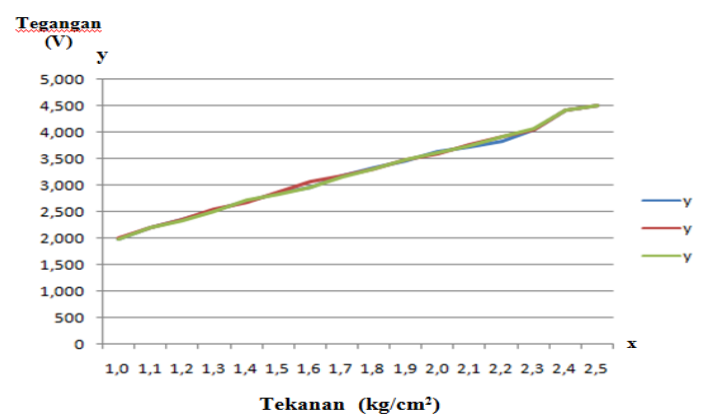

Gambar 15. Grafik Repeatibility berdasarkan Output Tegangan I,II, dan III

Pengujian alat pendeteksi tekanan kerja pompa bahan bakar menghasilkan data yang linear dan repeatibility $>=0$, sensor dan rangkaian yang dirancang menghasilkan data yang sama, pengujian alat dilakukan secara berulang-ulang. 


\section{SIMPULAN}

Perancangan alat pendeteksi tekanan kerja pompa bahan bakar terdiri dari perancangan desain, validasi desain, revisi desain, dan uji coba produk dilakukan sebanyak 3x. Pembuatan alat pendeteksi tekanan kerja pompa bahan bakar dimulai dengan pembuatan rangkaian pengontrol led dan menghubungkannya dengan pressure sensor serta pompa bahan bakar. Unjuk kerja alat ditinjau dari linearitas menghasilkan data yang linear antara tekanan dan tegangan yang dihasilkan oleh sensor. Repeatibility $=0$, artinya meskipun dilakukan beberapa kali percobaan, tetap menghasilkan data yang sama.

\section{SARAN}

Disarankan kepada pengguna kendaraan dengan sistem EFI, untuk memasang alat indikator pendeteksi tekanan kerja pompa bahan bakar, agar pengguna selalu mengetahui kondisi kinerja pompa bahan bakar.

Disarankan untuk penelitian lanjutan, menggunakan rentangan sensor yang tekanannya lebih tinggi, agar bisa mendeteksi untuk semua jenis mobil dengan sistem EFI (Gasoline Engine).

Disarankan untuk penelitian lanjutan, indikator led menyala secara bergantian berdasarkan variasi tekanan kerja pompa bahan bakar, agar dapat menghemat pemakaian arus listrik.

\section{DAFTAR PUSTAKA}

D. Patranabi. (2003). Sensor and Transducer. Second edition. New York: Phi Learning Pvt. Ltd.I

Fraden, Jacob. (2010). Handbook of Modern Sensors. Physics, Designs, and Applications. New York: acid-free paper.

Hesketh Peter. (2006). Chemical Sensors 7. New Jersey. USA: Electrochemical Society.
Kherrat. A. (2010) Chemical Sensor. Vol 38, No 8. New Jersey. USA: Electrochemical Society.

Middelhoek, S. and Hoogerwerf A.C. Smart sensors: Sensors Actuators 8(1), 39$48,1985$.

Sinclair I. R. (2001). Sensor and Transducers. Third Edition. Boston: Printed and bound in Great Britain.

Sugiyono. (2004). Metode Penelitian.Bandung: Alfabeta

Toyota Computer Controlled System. Training Manual. (1996). Jakarta : PT. Toyota Astra Motor.

Toyota Engine 5A-FE. Training Manual. (1996). Jakarta: PT Toyota Astra Motor

Toyota New Step 1. Training Manual. Jakarta: PT Toyota Astra Motor.

Walter, Borg R dkk. (1989). Educational Research. An introduction, Fifth Edition: Longman.

http://id.wikipedia.org/wiki/Regresi_Linier _Sederhana

http://id.wikipedia.org/wiki/Mekanika_fluid a

http://www.pressuresensorsuppliers.com/SS 204-Series-Automotive-PressureSensor.html 